\title{
СУЩНОСТЬ СОЦИО-ЭКОЛОГО-ЭКОНОМИЧЕСКИХ СИСТЕМ В ПРОЦЕССЕ ФОРМИРОВАНИЯ УСТОЙЧИВОГО ИСПОЛЬЗОВАНИЯ ЗЕМЕЛЬНЫХ РЕСУРСОВ
}

\author{
(C) 2012 г. Л. Г. Долматова, И. А. Петрова
}

\section{Новочеркасская государственная мелиоративная академия}

В статье рассмотрены основные положения устойчивого развития соиио-экологоэкономических систем, их взаимосвязь с внутренними и внешними условиями в процессе использования земельных ресурсов. Проанализированы основные показатели и критерии, характеризующие эффективность их использования.

Ключевые слова: земельныле ресурсы; экономика; сельское хозяйство; экология; производство; оценка; устойчивость.

In clause the basic rules (situations) of social, ecologic and economic systems 'stable development are considered, their interrelations with internal and external conditions during the exploitation of ground resources. The basic parameters and criteria, which describe the efficiency of the exploitation, are analyzed.

Key words: ground resources; economy; an agriculture; ecology; manufacture; an estimation; stability.

В современных условиях хозяйствования землепользования, представляющие собой сложные социо-эколого-экономические системы, имеющие определенные пространственно-структурные характеристики, испытывают сильнейшие негативные воздействия различных природных и антропогенных факторов, что создает реальную опасность для экологической обстановки в Российской Федерации.

Основные причины этого процесса кроются в конфликтном взаимодействии человека и природной среды, которое проявляется в усилении экономического давления, в нерациональной по своему характеру практике использования земельных ресурсов.

Всё это вызывает необходимость применения экосистемного подхода в управлении землепользованием как эколого-экономической системой. Основываясь на взаимосвязи и взаимозависимости сельскохозяйственного производства, экологических процессов, среды жизнедеятельности человека и интегрируя, таким образом, экономику, экологию и социальные явления, параметры, рассматриваемые ранее как внешние для экономической системы, должны стать для нее внутренними.

В научной литературе эколого-экономическая система определяется как организационное сочетание устойчивых технических, экономических, экологических и других типов связей. Однако данное определение не учитывает характер и целевую направленность указанных взаимосвязей, особенно их социальный аспект.

Поэтому устойчивой эколого-экономической системой можно назвать систему, функционирующую в условиях сложившейся институциональной среды, при соблюдении сформированных и формирующихся принципов устойчивого развития. Эколого-экономическая система приобретает форму устойчивого состояния в случае, если в результате столкновения природных, производственных, социальных, экономических и прочих интересов достигается некоторый компромисс в процессе выполнения каждой из пере- 
численных подсистем своей индивидуальной цели.

По нашему мнению, наиболее адекватным требованием устойчивого развития является рассмотрение социо-эколого-экономической системы как совокупности экономических, экологических и социальных отношений по поводу эффективного использования природно-ресурсного потенциала (в рассматриваемом случае - земельных ресурсов) в процессе производства материальных благ для целей экономического роста и устойчивого развития землепользования.

Социо-эколого-экономическая система включает в себя ряд элементов. В первую очередь, это окружающая среда в форме ресурсного и экологического потенциала, или природных условий. Под «ресурсным потенциалом» в данном случае понимается природная среда как источник ресурсов для экономики, а под «экологическим потенциалом» - внешняя среда, обеспечивающая возможность эффективного функционирования, как отдельных звеньев сельского хозяйства, так и всей системы и экономики в целом.

Необходимо отметить, что, в отличие от экосистем, системы социо-эколого-экономические являются открытыми, поскольку в них происходит постоянный обмен веществом и энергией между тремя её составляющими: обществом, производством, природной средой. Кроме того, данные системы являются постоянно развивающимися, так как взаимосвязи между её элементами и сами элементы претерпевают постоянные изменения, и именно наличие и динамика данных связей определяют потенциальную и фактическую устойчивость и равновесность системы.

Однако, поскольку социо-эколого-экономическая система является открытой, а, следовательно, подвержена влиянию внешних факторов, то состояние равновесия в ней носит относительный и временный характер, являясь равновесием динамическим и имея несколько возможных траекторий развития. Именно обеспечение равновесия между существованием и жизнедеятельностью общества с его хозяйственной жизнью и окружающей природной средой является основой устойчивого развития землепользования.

Средством активного регулирующего воздействия на социо-эколого-экономиче- скую систему служит, прежде всего, сама агропроизводственная деятельность, продукты которой входят в эту систему и преобразуют её. Эта деятельность, опираясь на технический прогресс, осуществляется независимо от каждого конкретного хозяйства и требований экологии. С одной стороны, она обеспечивает увеличение производства биологического продукта и улучшение жизни людей, а с другой - процессы интенсивного землепользования нарушают экологическое равновесие. Для борьбы с ними необходимо введение запретов на осуществление определенных агротехнологических процессов, использование средств почвозащиты, проведение специальных мероприятий по восстановлению земельных ресурсов.

Эффективность земельного использования во многом определяется ландшафтом местности, его геоморфологией, где вводятся определенные ограничения в обработку почвы, выращивание тех или иных культур. В таких условиях землепользования образуются на ландшафтной основе, т. е. предусматривают адаптивное использование природных, биологических, технологических и трудовых ресурсов. Адаптивный экономико-экологический подход заключается в создании устойчивой, функционирующей, высокопродуктивной агроэкологической системы. Функциональными единицами являются агроценозы с соответствующими технологиями и территорией, на которой они присутствуют. Всё вместе это должно представлять единое неразрывное динамичное целое и обеспечивать условия для расширенного воспроизводства плодородия почв и экономически эффективное ведение сельскохозяйственного производства.

Поскольку в использовании земельных ресурсов объектом управления выступают как социально-экономические процессы, так и природные, которые не только изменяются под воздействием различных технологий, но и влияют на дальнейшую эффективность их применения, то целесообразно от чисто экономической оценки хозяйственных решений перейти к многокритериальной оценке социо-эколого-экономической эффективности как совокупному показателю результативности устойчивого землепользования.

Экономический механизм обеспечения 
социо-эколого-экономической эффективности использования земельных ресурсов выглядит следующим образом (рис. 1) [2].

Из представленной схемы видно, что эффективность процесса землепользования зависит от взаимного соответствия внутренних и внешних условий функционирования агроэкосистемы. К внешним условиям функционирования следует отнести факторы, определяющие процесс формирования земельных ресурсов: климат, рельеф, почвенный и растительный покров, хозяйственное использование земли и др. показатели, характеризующие экологическую емкость того или иного агроландшафта. В свою очередь, к внутренним условиям функционирования механизма землепользования относятся способы технологического воздействия, машины и механизмы, процесс управления, организационные формы использования земельных ресурсов.

Социо-эколого-экономическая эффективность характеризует совокупную экономическую результативность процесса производства сельскохозяйственной продукции с учетом влияния процесса использования земельных ресурсов на природную среду и развитие сельских территорий.

Этот показатель отражает результативность осуществления в процессе производства наряду с материальными и трудовыми затратами затраты, связанные с ликвидацией разрушений природной среды, возникающих в процессе сельскохозяйственной деятельности, например, эрозии почвы, а также потерь сельскохозяйственной продукции вследствие ухудшения экологического состояния окружающей среды.

Критерием социо-эколого-экономической эффективности сельскохозяйственного производства служит максимизация решения задачи по удовлетворению общественного спроса на продукцию сельского хозяйства, полученную с оптимальными производственными издержками при сохранении и воспроизводстве окружающей среды как в экологическом, так и в социальном плане.

При этом определение эколого-экономической эффективности использования земельных ресурсов в настоящее время базируется на основе показателей эколого-эко- номического ущерба и эффекта, общей (абсолютной) и сравнительной эколого-экономической эффективности [1].

Эколого-экономический ущерб, наносимый земле, используемой в сельском хозяйстве в качестве основного средства производства, проявляется в стоимостной оценке качественного ухудшения ее состояния, выражающегося, прежде всего, в ухудшении почвенного плодородия и потерях продукции в результате снижения продуктивности сельскохозяйственных угодий.

Общая эколого-экономическая эффективность использования земельных ресурсов определяется отношением годового объема полного эколого-экономического эффекта, представляющего собой разность между экономическими результатами сельскохозяйственной деятельности предприятий и вызвавшими их затратами, скорректированную на величину экономической оценки экологического ущерба, нанесенного сельским хозяйством природной среде, к полному объему затрат, вызвавших эколого-экономический эффект, включая природоохранные мероприятия.

Наиболее эффективным следует считать вариант, для которого показатель общей (абсолютной) эколого-экономической эффективности имеет наибольшую величину. Однако, как мы можем видеть, в существующей методологии оценки эколого-экономической эффективности землепользования не учитываются параметры социальной эффективности, которая является обязательной при реализации концепции устойчивого развития.

Таким образом, социо-экономическая оценка эффективности использования земельных ресурсов может быть выражена коэффициентом доходности. При этом сбалансированная система показателей социо-эколого-экономической эффективности может подвергаться изменениям. Это процесс естественный и даже необходимый, поскольку любая система живет только до тех пор, пока способна изменяться в ответ на изменения окружающей среды.

Система индикаторов устойчивого развития использования земельных ресурсов должна отражать качественные и количественные характеристики планируемых изменений в 


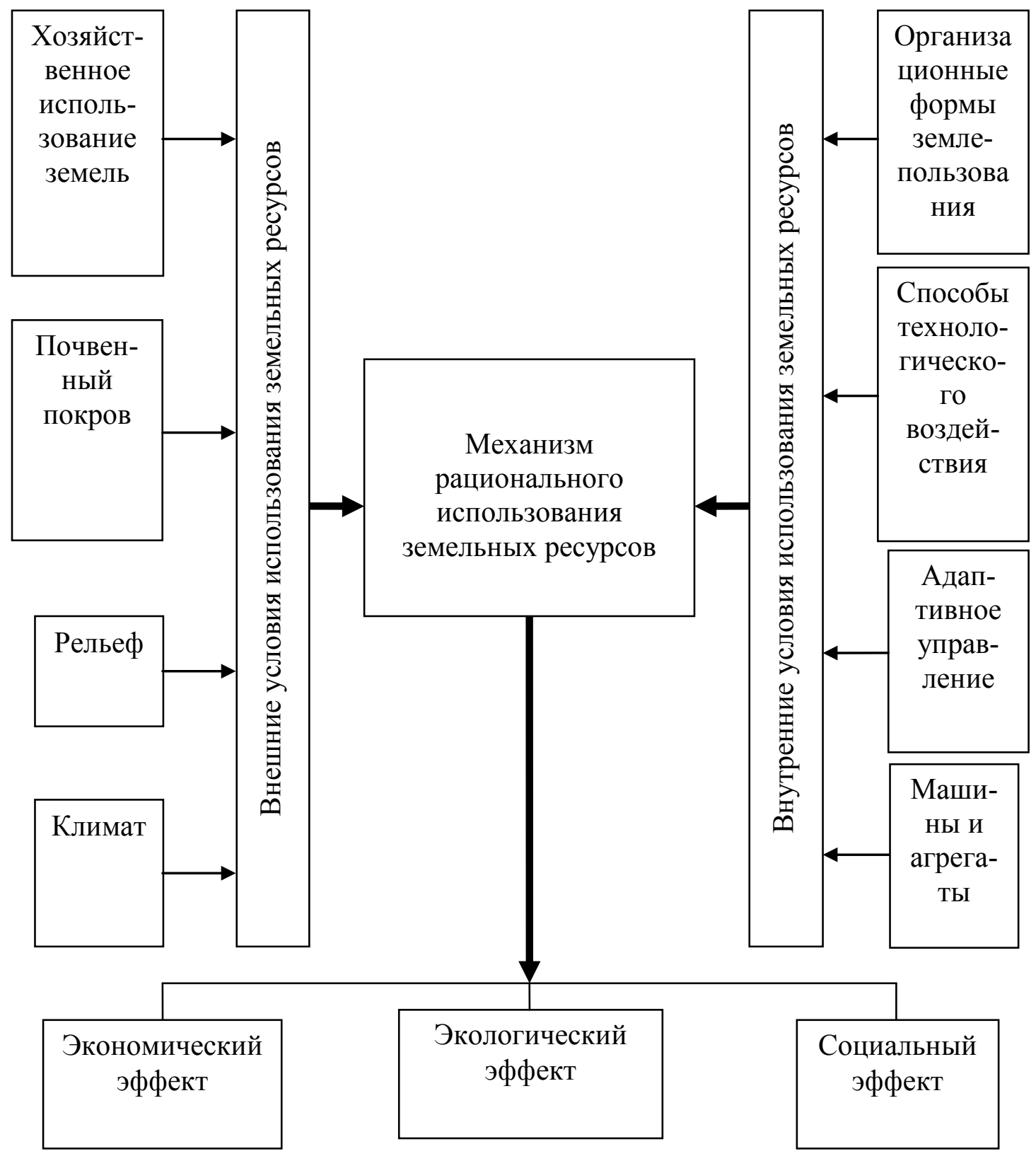

Рис. 1. Концептуальный механизм обеспечения социо-эколого-экономической эффективности использования земельных ресурсов

системе использования земельных ресурсов с учетом экологических требований. Планируемые изменения следует отслеживать по трем группам индикаторов: экономическим, социальным, экологическим. Планирование таких изменений, естественно, преследует цель достижения стабильной прогрессивной тенденции по названным группам показателей.

\section{Литература}

1. Бирюк T. A. Обоснование стратегии устойчивого развития аграрного землепользования: экономические императивы, природохозяйственные приоритеты: Автореферат дисс. ... к.э.н. - Майкоп, 2008.

2. Долматова Л. Г. Социо-эколого-экономические аспекты территориального планирования использования и охраны земельных ресурсов: монография. - Ростов н/Д.: СКНЦ ВШ ЮФУ, 2012. - 260 c. 


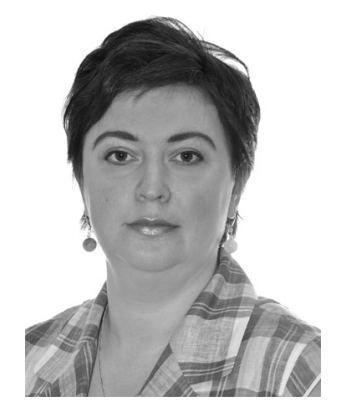

Людмила Георгиевна Долматова - кандидат экономических наук, доцент кафедры «Землеустройство» Новочеркасской государственной мелиоративной академии

Lyudmila Georgievna Dolmatova - Ph.D., Candidate of Economics, docent at the Land Reclamation department of Novocherkassk State Academy of Land Reclamation.

346400, Ростовская обл., г. Новочеркасск, ул. Фрунзе, д. 3

3 Frunze st., 346400, Novocherkassk, Rostov reg., Russia

Тел.: +7 (8635) 27-96-36; e-mail: dolmatoval1971@mail.ru

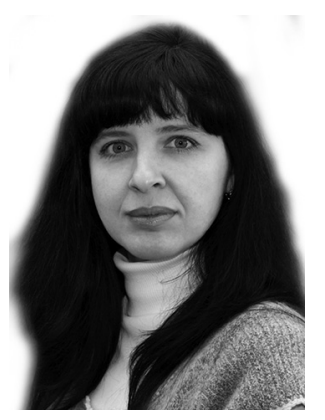

Ирина Альбертовна Петрова - кандидат сельскохозяйственных наук, доцент кафедры «Землеустройство» Новочеркасской государственной мелиоративной академии

Irina Albertovna Petrova - Ph.D., Candidate of Agricultural Sciences, docent at the Land Reclamation department of Novocherkassk State Academy of Land Reclamation.

346400, Ростовская обл., г. Новочеркасск, ул. Троицкая, д. 80-а, кв. 98 80-a Troitskaya st., app. 98, 346400, Novocherkassk, Rostov reg., Russia Тел.: +7 (8635) 27-96-36; e-mail: ngma@ngma.su 